\title{
Acute confusion in a young man
}

\author{
Richard J Butterworth, Philip MW Bath
}

A 39-year-old man was admitted as an emergency after being found by his mother in a confused and disorientated state. She described finding his flat in a mess, that he did not recognise her and that he was acting strangely. When she had visited the previous evening he had been fit and well and had not complained of any prodromal symptoms.

Six years previously, grade IIB nodular sclerosing Hodgkin's lymphoma was diagnosed following the biopsy of cervical lymph node swellings. This was successfully treated with six courses of chemotherapy and 20 courses of adjuvant radiotherapy to the neck and shoulder region. The radiation dose totalled $35 \mathrm{~Gy}$ in 20 fractions over a four-week period. Subsequent clinical and radiological review confirmed disease remission. In 1993 thyroxine (150 mg daily) was started for biochemical hypothyroidism. He had no other medical history of note, in particular no vascular problems or previous hypertension. He lived alone and smoked 10-20 cigarettes per day.

On arrival in hospital he was found to be disorientated in time, place, and person, and slightly drowsy. He was apyrexial, had no signs of meningism and no skin rashes. Cardiovascular (including blood pressure), respiratory, and abdominal examination was normal. A neurological examination highlighted dysfunction of the dominant cortex with evidence of dysphasia (expressive and receptive) and left/right disorientation. In addition, mild motor loss was noted in the right arm and face as was a right homonymous hemianopia. The results of initial haematological and biochemical screens were normal as was chest X-ray. An urgent head computed tomography (CT) scan with contrast was performed in view of the drowsiness.

Department of Medicine, King's College School of Medicine and Dentistry, Bessemer Road, London SE5 9PJ, UK

RJ Butterworth PMW Bath

Accepted 26 April 1995

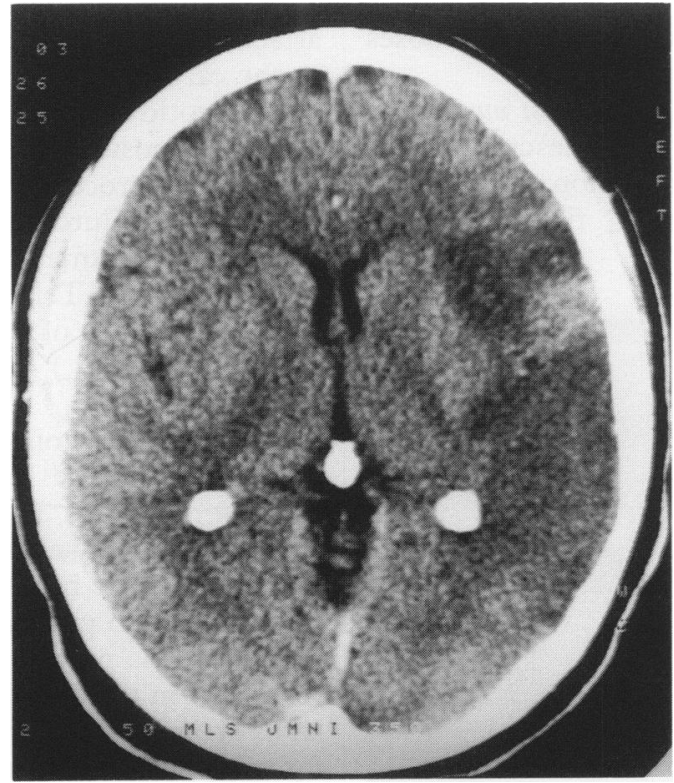

\section{Questions}

1 What does the CT scan in figure 1 show?

2 What is the most likely cause of these changes?

3 What is the most likely cause of this event? 


\section{Answers}

QUESTION 1

The CT scan shows a left parieto-occipital low attenuation area consistent with an infarct with evidence of haemorrhagic transformation within it.

\section{QUESTION 2}

A left parietal, middle cerebral artery stroke presenting as a total anterior circulation infarction. ${ }^{1}$ This was confirmed by a brain single positron emission CT (SPECT) scan performed the following day revealing a large perfusion defect in the left cortical region (figure 2).

\section{QUESTION 3}

Accelerated atherosclerosis of the left internal carotid artery secondary to carotid radiotherapy. Carotid Doppler studies in this man suggested $40 \%$ stenosis of the right internal carotid artery while the left one was occluded. These findings were confirmed on a carotid angiogram (figure 3).

\section{Discussion}

A connection between radiation and clinically significant accelerated atherosclerosis has been known for almost 40 years. Initially a link between myocardial infarction and radiotherapy of the breast was noted, ${ }^{2}$ and subsequently a case of bilateral carotid disease following cervical radiation for Hodgkin's disease was reported. ${ }^{3}$ Two reviews in 1989 cite a total of about 50 reported cases of carotid stenoses after local radiotherapy.,5

Histological reports either at post mortem or during carotid endarterectomy describe atheromatous material and calcification of the intima with marked peri-arterial fibrosis. ${ }^{5}$ The

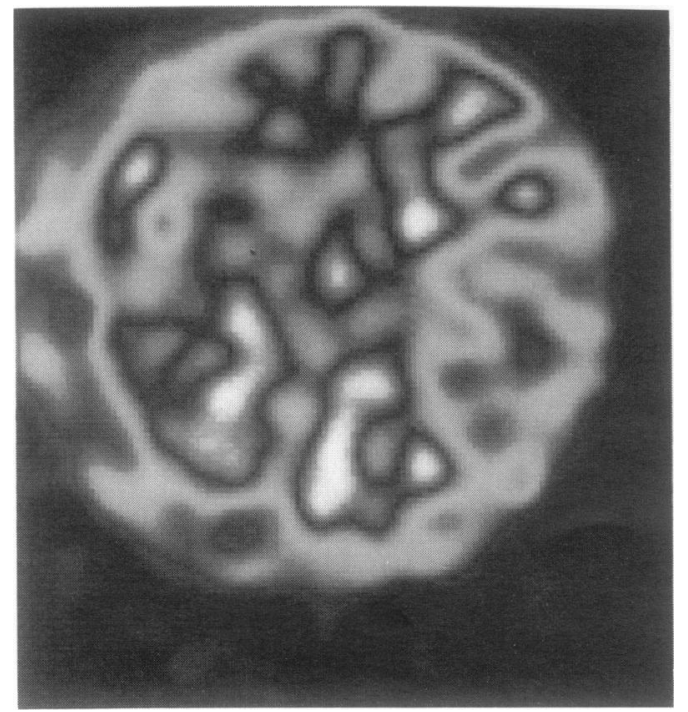

Figure 2 SPECT scan showing left cortical hypoperfusion

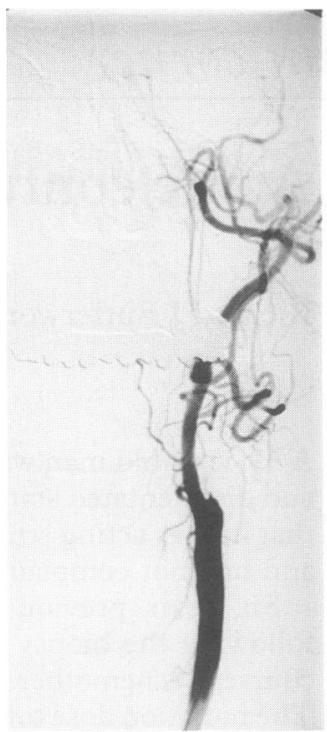

A

Figure 3 Carotid angiograms of A) occluded left internal carotid artery and B) stenosed right internal carotid artery

primary pathogenesis of radiation-induced atherosclerosis is unclear. Animal models report marked endothelial changes seen on electron microscopy within $\mathbf{4 8}$ hours of radiation while there is synergy between radiation and hypercholesterolaemia for inducing atherosclerosis. $^{4-6}$

Carotid stenosis secondary to atherosclerosis is the main cause of $10 \%$ of cerebral infarctions. All patients suffering from transient ischaemic attacks or mild cerebral infarction attributable to the carotid territory should be investigated with carotid Doppler studies. Patients with $>50 \%$ stenosis who are candidates for surgery should then proceed to carotid angiography. In 1991 both the European Carotid Surgery Trial ${ }^{7}$ and the North American Symptomatic Carotid Endarterectomy Trial $^{8}$ published data showing definite benefits of surgery in patients with severe $(70-99 \%)$ internal carotid artery stenosis.

Patients undergoing radiotherapy involving areas where large arteries are present (eg, mediastinum and neck) should be strongly advised to cease smoking and have coexisting hypertension or hyperlipidaemia treated aggressively. Such patients might reasonably also take aspirin prophylactically. When fuller results from the asymptomatic carotid surgery trials are known, a strong argument may exist for routine and regular carotid Doppler scanning of these patients. ${ }^{9}$

\section{Final diagnosis}

Cerebrovascular accident following radiotherapy for Hodgkin's disease

Keywords: stroke, carotid stenosis, radiotherapy, Hodgkin's disease 
1 Bamford J, Sandercock P, Dennis M, Burn J, Warlow C. Classification and natural history of clinically identifiable subtypes of cerebral infarction. Lancet 1991; 337: 1521-6. 2 Pearson HES. Coronary occlusion following thoracic 2 Pearson HES. Coronary occlusion following

3 radiotherapy. Proc $R$ Soc Med 1957; 50: 516 . Heidenberg WJ, Lupovitch A, Tarr N. "Pulseless disease"
complicating Hodgkin's disease. $\mathcal{F} A M A$ 1966; 195: 488-91. 4 Murros KE, Toole JF. The effect of radiation on carotid arteries. Arch Neurol 1989; 46: 449-55.

5 Atkinson JLD, Sundt Jr TM, Dale AJD, Cascino TL Nichols DA. Radiation associated atheromatous disease of the cervical carotid artery: report of seven cases and review of the literature. Neurosurgery 1989; 24: 171-8.
6 Smith REA, Dobbs HA, Martin JF. Radiotherapy, leftsided breast cancer, and ischaemic heart disease. Br Heart $\mathcal{f}$ 1993; 69: 483-4.

7 European Carotid Surgery Trialists' Collaborative Group. MRC ECST: interim results for symptomatic patients with severe $(70-99 \%)$ or with mild $\left(0-29^{\circ}\right)$ carotid stenosis Lancet 1991; 337: 1235-43.

8 North American Symptomatic Carotid Endarterectomy Trial Collaborators. Beneficial effect of carotid endarterectomy in symptomatic patients with high grade carotid stenosis. N Engl f Med 1991; 325: 445-53.

9 Roberts J. Surgery best to prevent strokes, say US researchers. $B M \mathcal{F}$ 1994; 309: 898-9.

\title{
Dysphagia in a diabetic patient
}

\author{
G Piédrola, E López, D Piédrola, G Plaza
}

A 42-year-old man presented with a four-day history of pharyngeal discomfort and slight difficulty swallowing. There was no history of shivering, fever, cough or expectoration. Since the age of 20, he had been taking insulin for type I diabetes mellitus.

On examination of his mouth in the Emergency Department pyorrhea was noted. There was also a fullness in the left cervical area, without other findings of interest. Indirect laryngoscopy showed no clear evidence of obstruction, or any other organic lesion in the endolarynx hypopharynx.

Investigations revealed a leucocytosis $(20000 \mathrm{l} / \mathrm{mm}$ with aleft deviation), hyperglycaemia $(333 \mathrm{mg} / \mathrm{dl}$ ) with glucosuria greater than $1000 \mathrm{mg} / \mathrm{dl}$, and ketonuria greater than $80 \mathrm{mg} / \mathrm{dl}$. Arterial blood gas analysis revealed a pH 7.28 and $\mathrm{HCO}_{3}$ of $13 \mathrm{mmol} / \mathrm{l}$. An urgent computer tomography (CT) scan of the neck was carried out (figures 1 and 2).

\section{Departments of Endocrinology and Otolaryngology, Ramon y Cajal Hospital, Ctra Colmenar Km 9.100, 28034 Madrid, Spain G Piédrola \\ E López \\ D Piédrola \\ G Plaza}

Accepted 26 April 1995

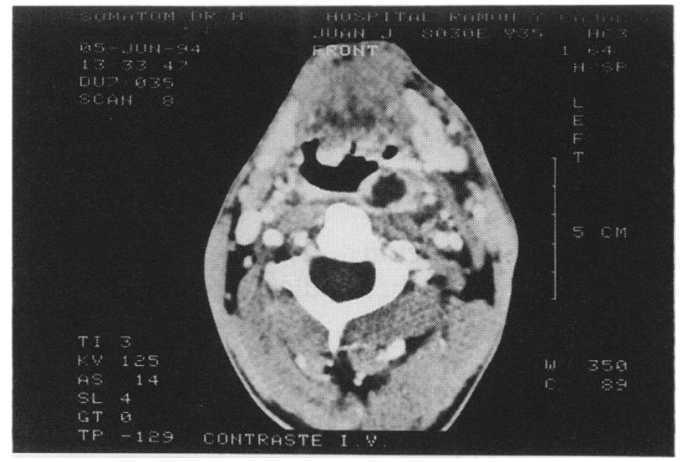

Figure 1

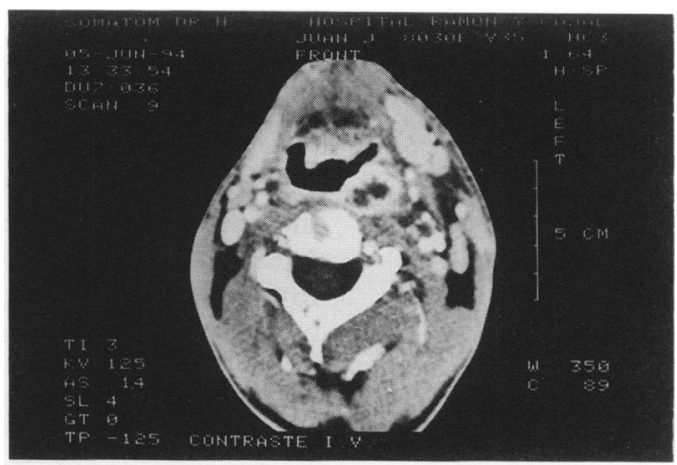

Figure 2

\section{Questions}

1 What is the most likely cause of the CT changes?

2 What treatment would you advise?

3 What are the most frequent complications in this pathology? 